\title{
Hastaların Ameliyat Sonrası Kompresyon Çorabı Kullanma Durumlarının Değerlendirilmesi*
}

\author{
Evaluation of Using Compression Stocking in Postoperative Patients
}

\author{
Zeynep KIZILCIK ÖZKAN**, Ümmü Yıldız FINDIK***, Seher ÜNVER****
}

İletişim/Correspondence: Zeynep KIZILCIK ÖZKAN Adres/Address: Trakya Üniversitesi, Sağlık Bilimleri Fakültesi, Hemşirelik Bölümü, Cerrahi Hastalıkları Hemşireliği AD, 22030 Balkan Yerleşkesi Edirne Tel: 028421330 42/2131 Fax: 02842126107

E-mail: zeynepozkan@trakya.edu.tr

$\ddot{O} Z$

Amaç: Bu çalışmanın amacı, ameliyat sonrası hastaların kompresyon çorabı kullanımını değerlendirmektir.

Yöntem: Tanımlayıcı nitelikte olan bu çalışma, bir üniversite hastanesinin genel cerrahi bölümü hastalarının katılımıyla 15 Kasım-15 Aralık 2014 tarihleri arasında gerçekleştirildi. Veriler, çalışmaya katılmaya gönüllü olan 75 hastadan elde edildi. Anket formu, literatürden yararlanılarak araştırmacılar tarafindan hazırlandı ve uygulandl. Toplanan veriler SPSS 19.0 paket programı ile frekans ve yüzde kullanılarak analiz edildi.

Bulgular: Hastaların kompresyon çorabı kullanımına ilişsin en çok yardımsız giyememe, terletme gibi problemlerden rahatsızlık duyduğu saptandı. Katılımcıların \%60'ı kompresyon çorabının kullanımı hakkında bilgilendirilmiş olmasına rağmen kompresyon çorabının kullanımında yanlış uygulamaların (gece giyme vb.) yapıldı̆̆̆ belirlendi.

Sonuç: Katılımcıların kompresyon çorabı kullanımı hakkında yeterli bilgi almadıkları ve uygulamada da yanlışlıklar yaptıkları saptandı. Hastaların sıklıkla kullandıkları kompresyon çorabının kullanımına iliş̧in bilgilendirmenin hekim ve hemşirelerce detayl yapılmasina önem verilmelidir.

Anahtar Kelimeler: Ameliyat sonrası dönem, kullanım sorunları, kompresyon çorabı.

\section{ABSTRACT}

Aim: The aim of this study is to evaluate the using of compression stockings in postoperative patients.

Method: This descriptive study was conducted in a University hospital with participation of the general surgery department patients between November 15 and December 15 in 2014. The data were obtained from 75 patients who volunteer to participate. The questionnaire was prepared by the researchers benefit from literature and applied. The data were analyzed using frequency and percent wit SPSS 19.0 software package.

Results: The patient's complaint concerning the use of compression stockings are failure to wear stockings without help and sweating. Although $60 \%$ the participants were informed about the use of compression stockings, $i t$ was determined that made incorrect practices (night wear etc.) in using of the compression stocking.

Conclusion: Participants didn't have adequate information about use of compression stocking and they were accidentally detected in practice. Doctors and nurses should be given more detail information to patients about compression stockings. Keywords: Postoperative, usage of problems, compression stocking.

*9. Ulusal Türk Cerrahi ve Ameliyathane Hemşireliği Kongresi’nde poster bildiri olarak sunulmuştur (12-15 Kasım 2015, Muğla), **Arş. Gör. Trakya Üniversitesi Sağllk Bilimleri Fakültesi, Hemşirelik Bölümü, *** Doç. Dr. Trakya Üniversitesi Sağllk Bilimleri Fakültesi, Hemşirelik Bölümü, ****Yrd. Doç. Dr. Trakya Üniversitesi Sağllk Bilimleri Fakültesi, Hemşirelik Bölümü

Yazının gönderilme tarihi: 20.10.2015

Yazının basım için kabul tarihi: 29.01.2016 


\section{GíRiş}

Venöz trombo emboli (VTE), ameliyat sonrasında yaygın görülen, mortalite ve morbiditeye yol açabilen önlenebilir bir komplikasyondur (Sarıül ve Tanyeli 2007; Thenganatt ve Geerts 2006). VTE'nin en sık görülen formu derin ven trombozudur (DVT) (Sarıgül ve Tanyeli 2007). Spinal kord yaralanmaları, majör venöz yaralanmalar, şiddetli infeksiyonlar, paralizi, santral venöz katater, immobilizasyon, hormon tedavisi, obezite, hamilelik, geçmişte DVT öyküsü, kanser ve sigara alışkanlığı DVT'nin risk faktörlerindendir (Lassila 2013; Samama, Dahl, Quinlan, Mismetti ve Rosencher 2003; Şerifoğlu, Bilgen, Atıc1, Bilgen ve Yılmazlar 2007). Ameliyat sonrasında uzun süreli yatak istirahati ve immobilizasyon venöz kan akımını bozarak özellikle bacak ve pelvik venlerinde venöz staza ve trombüse yol açmaktadır (Kurtoğlu ve Sivrikoz 2008). Ameliyat geçiren bireylerde DVT riskinin 2 kat yüksek olduğu saptanmıştır (Dirimeşe ve Yavuz 2010). DVT yaygınlığ genel cerrahide \%15-40, nöroşirurjide \%15-40, kalça ve diz protezi, kalça k1rığı cerrahisinde \%40-60 olarak tespit edilmiştir (Geerts ve ark. 2004). Düşük cerrahi risk taşıyan hastaların (30 dakikadan az süren operasyon ve ek risk faktörleri taşımayanlar) \%10, minör cerrahi işlem geçiren ve ek risk faktörlerine sahip olan hastaların \%10-\%30 ve majör cerrahi işlem geçiren ve risk faktörü taşıyan hastaların \%50-80 DVT risk grubunda olduğu belirtilmektedir (Lassila 2013).

Uygun tromboprofilaksinin kullanımı ile DVT önlenebilir (Morrison 2006; Sachdeva, Dalton, Amaragiri ve Lees 2010). Derin ven trombozunun önlenmesinde kullanılan mekanik yöntemler; kompresyon çorabı (KÇ), sıralı pnömatik KÇ ve filtrelerdir (Aydın ve ark. 2005). Cerrahi girişim deneyimleyen hastalarda KÇ'nin kullanımı DVT'nin önlenmesinde etkin ve güvenilir bir girişim olarak kabul edilmektedir (Autar 2009; Sajid, Desai, Morris ve Hamilton 2012; Walker ve Lamont 2008; Vascular Disease Foundation 2012). Kullanılan farmakolojik ve mekanik yöntemlerle trombüs oluşumunun engellenmesi, emboli komplikasyonunun azaltılması, klinik tablonun düzel- tilmesi ve tekrarlamaması amaçlanmaktadır. Kompresyon çorabı damar çapını daraltarak, damar basıncın1 azaltmakta ve venöz dönüşü artırarak venöz stazı ve trombüsü engellemektedir (Aydın ve ark. 2005; Oğlakçıoğlu ve Marmaralı 2009; Taylan 2008). KÇ'ler kontrendikasyon yoksa ameliyat edilecek hastalarda profilaktik olarak kullanılabilir (Scottish Intercollegiate Guidelines Network 2010). Tek başına kullanıldığında, DVT sıklığını \%60 oranında azalttığı, profilaksi amaciyla mekanik ya da farmakolojik bir yöntemle birlikte kullanıldığında \%85'e kadar etkinlik sağladığı Autar (2009)'ın çalışmasında belirtilmiştir. Kompresyon çorabı diğer metotlarla birlikte olsun olmasın doğru kullanıldığı takdirde cerrahi hastalarında DVT riskini önemli ölçüde azaltmaktadır (NICE 2012; Winslow, Debra ve Brosz 2008). Ancak yüksek riskli cerrahi hastalarında tek başına Kompresyon çorabı önermek için yeterli kanıt yoktur (NICE 2012). Kompresyon çorabı yanlış kullanıldığında cilt bütünlüğünü bozabilmekte, yararlılığ 1 azaltabilmekte ve tromboz riskinde artışa yol açabilmektedir (Dennis ve ark. 2009; Whitley 2002; Winslow ve ark. 2008).

Kompresyon çorabının etkin olabilmesi için, bireyin uygun ölçülerde KÇ kullanması gerekmektedir (Bozkurt ve ark. 2008; Nicolaides ve ark. 2008). Kompresyon çorabının tedavide etkinliği çorabın bacağa uyguladığı basınca bağlıdır ve kan akım dinamiğine daha çok yardımcı olabilmek amacıyla, çorapların basınçları ayak bileğinde en yüksek, baldırlarda daha düşük, uylukta daha da düşük olarak ayarlanmıştır. Böylece ayak bileğine baldırdan, baldıra uyluktan daha fazla basınç uygulandığından kan akımı aşağıdan yukarıya doğru yönlendirilmiş olur (Özbayrak 2009; Taylan 2008). Kompresyon çorabının doğru boyutlandırılmasını sağlamak için ayak bileği, diz, baldır ve uyluk çevresinin ölçümü ile bacak uzunluğu ölçümü yapılmalıdır (Dennis ve ark. 2009; Whitley 2002). Ölçümler sabahın erken saatlerinde ve mümkünse herhangi bir egzersiz yapılmamış olarak ve de uzun süre ayakta kalmadan önce yapılmalıdır (Whitley 2002). Hastalara ameliyat öncesi dönemde KÇ kullanımının profilaksi etkinliği ve riskleri açısından sözlü ve yazılı bil- 
gi verilmeli ve hastalar ameliyat sonrası en kısa sürede mobilizasyon için teşvik edilmelidir (The Joanna Briggs Institute 2008). KÇ’nin etkinliğinin sağlanmasinda boyutlandırma kadar doğru uygulama da önemlidir (Bozkurt ve ark. 2008; Nicolaides ve ark. 2008). Hastalara KÇ'lerin nasıl giyileceği konusunda ve ürünün kullanımı hakkında bilgi eğitimli sağlık çalışanı tarafından verilmelidir ve hastalar KÇ’ yi giymesi için cesaretlendirilmelidir (NICE 2010; The Joanna Briggs Institute 2008). Hasta, KÇ'yi giyerken şu noktalara dikkat etmelidir; KÇ venlerin boş olduğu sabahın erken saatlerinde giyilmelidir ve hasta yataktan kalkmadan önce, bacaklarını 5-10 dakika yukarı kaldırmalıdır (Bozkurt ve ark. 2008; Nicolaides ve ark. 2008). KÇ el içinde toplanmalı, ayaklar yataktan sarkıtılmadan, bacaklar yukarı doğru sıvazlanarak giyilmelidir. Külotlu KÇ giyiliyorsa, çorap her iki bacakta diz eklemini geçtikten sonra ayağa kalkarak çorabın kalça kısmı yerleştirilmelidir (Milli Eğitim Bakanlığı 2012). Gün içinde KÇ ile dolaşılmalı, gece yatmadan önce çıkarilmalıdır (Bozkurt ve ark. 2008; Nicolaides ve ark. 2008; Taylan 2008).

Cilt bütünlüğü ve kanlanması topuklar ve kemik ç1kıntılarını da kapsayacak şekilde günde 2-3 kez kontrol edilmelidir (NICE 2010; The Joanna Briggs Institute 2008). Ağrı, cilt bütünlüğünde bozulma, cilt renginde değişme varsa KÇ kullanımına devam edilmemelidir (NICE 2010). KÇ giyilmeden önce bacakların kuru olduğundan ve giyildikten sonra da KÇ'nin kat kat olmadığından emin olunmalıdır (The Joanna Briggs Institute 2008; Vascular Disease Foundation 2012). KÇ'ler üretici talimatlarına uygun olarak ya da 1lık su $\left(40 C^{0}\right)$ ve sabun kullanarak her gün yıkanmalıdır. Yıkandıktan sonra bir havlu aracılığıla fazla suyu alınmalıdır, kesinlikle sıkılmamalı veya asılmamalı ve ütü yapılmamalıdır (Whitley 2002). KÇ'ler elastikiyetini kaybetmeden 6-12 ayda bir de değiştirilmelidir (Taylan 2008).

Kompresyon çoraplarının; külotlu, diz boyu, uyluk boyu, sadece diz ayak bileği koruma amaçlı olarak piyasada çeşitleri mevcuttur (Whitley 2002).
Kompresyon çorapları, kanıtlanmış periferik arter hastalığı veya şüphesi olan-çorabın deriye zarar vereceğ $i$ durumları (örn; deri grefti, kangren vb.) yaşayan-hastalarda kullanılmamalıdır (NICE 2010; Scottish Intercollegiate Guidelines Network 2010).

İlgili literatür değerlendirildiğinde, KÇ’lerin mekanik profilaksi amaciyla hastalarda $\% 67.9$ ve $\% 45.5$ oranında tek başına kullanıldığı belirtilmiştir (Altıntaş ve ark. 2008; Sage, McGee, Emed 2008). Ancak hastaların ameliyat sonrası Kompresyon çorabı kullanma davranışları ile ilgili sınırlı bilgi vardır. Bu bağlamda bu çalışmanın amacı, ameliyat sonrası hastalarda kompresyon çorabı kullanımını değerlendirmektir. Çalışmanın araştırma soruları aşağıdaki gibidir.

1. Hastaların kompresyon çorabı kullanımına ilişkin olumsuz görüşleri nelerdir?

2. Hastaların kompresyon çorabı kullanımında yanlış uygulamaları var midir?

\section{YÖNTEM}

\section{Araştırmanın Evreni ve Örneklemi}

Tanımlayıcı nitelikte olan bu çalışma, bir üniversite hastanesinin genel cerrahi servisinde ameliyat edilen hastaların katılımıyla 15 Kasım-15 Aralık 2014 tarihleri arasında gerçekleştirildi. Çalışma öncesinde kurumdan yazılı izin ve katılımcılardan sözlü olur alınd1. Raju, Hollis ve Neglen (2007)'nin yaptıkları çalışmadaki bulguların dahilinde kompresyon çorabının kullanımına ilişkin saptanan semptomun oranına göre (cilt bütünlüğünde bozulma \%2) \%95 güven düzeyinde ve tolerans oranı \%5 öngörülerek örneklem sayısı 75 kişi olarak bulundu.

\section{Veri Toplama Araçları}

Verilerin toplanmasında sosyo-demografik özellikler ve KÇ’nin kullanımına ilişsin literatür doğrultusunda araştırmacılar tarafindan hazırlanmış (Kahn, Elman, Rodger ve Wells 2003; Partsch, Pannier, Partsch ve Rabe 2005; Winslow ve ark. 2008) olan soruları (kullanım amacı, yanlış kullanım, yaşanan problemler vb.) içeren 33 maddelik anket formunu kullanıldı. Soru for$\mathrm{mu}$; yaş, cinsiyet, eğitim durumu, medeni durum vb. 
sosyo-demografik özellikler ile kronik hastalık varl1ğı, KÇ kullanım amacı ve tipi, KÇ kullanımı hakkında bilgi alma durumu, KÇ'ye ilişkin şikayetlerin varlığını saptayan soruları içerdi.

\section{Verilerin Toplanması}

Anket formu hasta odasında ameliyat öncesi en az 24 saat KÇ kullanmış ve ameliyat sonrası 24. saati doldurmuş olan hastalar ile yüz yüze görüşme metodu kullanılarak maksimum 10 dakikada araştırmacılar tarafindan dolduruldu.

\section{Verilerin İstatistiksel Analizi}

Toplanan veriler SPSS 19.0 paket programı ile frekans ve yüzde kullanılarak analiz edildi.

\section{Araştırmanın Etik ve Yasal Yönleri}

Çalışma öncesinde kurumdan çalışma izni, etik kurul izni (BAEK-05.11.2014/155/20-02) ve katılımc1lardan sözlü olur alındı. Çalışmaya yalnızca gönüllü hastalar dahil edildi. Araştırmacının kendini tanıtmasının ardından, çalışma hakkında bilgi verilerek anket formları dolduruldu. Bilgilerin bilimsel amaç dışında kullanılmayacağı ve üçüncü şahıslar ile paylaşılmayacağ1 hakkında bilgilendirme yapıldı.

\section{Araștırmanın Sınırlılıkları}

Çalışmada tanımlayıcı istatistiklerden yararlanılması, gruplar arası uygun istatiksel testlerden yararlanılmamış olması çalışmanın sınırlılığıdır. Ayrıca ülkemizde benzer çalışmaya rastlanmadığından tartışma kısmında yurtdış1 yayınlar ile karşılaştırma yapılmıştır.

\section{BULGULAR}

Hastaların yaş ortalaması; $59.36 \pm 14.5$ yıl ve çorap kullanım süresi ortalaması $4.38 \pm 0.44$ gündü. Hastaların çoğunluğunu erkekler $(\% 57,3)$ oluşturmaktadır. Hastaların \%84'ünün ilköğretim mezunuydu ve \%66,7'sinin en az 1 tane sistemik hastalığı bulunmaktaydı (Tablo 1). Hastaların cerrahi işlemleri değerlendirilmesi yapıldığında ilk siralarda kolon-rektum (\%40), mide (\%18.6) ve safra kesesi (\%13.3) ameliyatlarının yer aldığı belirlendi.
Tablo 1. Hastaların Sosyo-Demografik Verilere Göre Dağılımı

\begin{tabular}{|l|l|c|c|}
\hline \multicolumn{2}{|c|}{ Sosyo-Demografik Veriler } & n & \% \\
\hline \multirow{2}{*}{ Cinsiyet } & Kadın & 32 & 42.7 \\
& Erkek & 43 & 57.3 \\
\hline \multirow{3}{*}{ Eğitim durumu } & İlköğretim & 63 & 84 \\
& Lise & 11 & 14.7 \\
& Lisans ve üzeri & 1 & 1.3 \\
\hline \multirow{2}{*}{ Sistemik hastalık } & Mevcut & 50 & 66.7 \\
& Yok & 25 & 33.3 \\
\hline
\end{tabular}

En çok kullanılan KÇ tipi, uyluk boyu $(\% 93,3)$ olarak saptandı. KÇ kullanımına ilişkin hastaların \%40’ı bilgi almadığını ifade etmiştir. Hastaların \%60’1 KÇ’nin pıhtıyı önlemeye yaradığını düşünmekteydi (Tablo 2).

Tablo 2. Hastaların KÇ Kullanımına İlişkin Verilerinin Dağılımı

\begin{tabular}{|l|l|c|c|}
\hline \multicolumn{2}{|c|}{ KÇ Kullanımına İlişkin Veriler } & n & \% \\
\hline KÇ tipi & Uyluk boyu & 70 & 93.3 \\
& Diz boyu & 5 & 6.7 \\
\cline { 1 - 2 } KÇ kullanma & Pihtıyı engelleme & 45 & 60 \\
amacı & Şişliği önleme & 4 & 5.3 \\
& Ağrı giderme & 1 & 1.3 \\
& Bilmiyorum & 25 & 33.3 \\
\cline { 1 - 2 } KÇ hakkında & Medikal & 32 & 42.7 \\
bilgi alınan kişi & Hemşire & 8 & 10.7 \\
& Hekim & 5 & 6.7 \\
& Bilgilendirilmedim & 30 & 40 \\
\hline
\end{tabular}

KÇ kullanımına ilişkin hastaların olumsuz görüşleri; yardımsız giyememe (\%88), terletme $(\% 76)$, yarar görmeme $(\% 62,7)$, sikma (\%40) olarak belirlendi (Tablo 3).

Tablo 3. Hastaların Kompresyon Çorabına İlişkin Olumsuz Görüşleri

\begin{tabular}{|l|l|l|}
\hline Olumsuz Görüşler & n* & \% \\
\hline Yardımsız giyememe & 66 & 88 \\
Terletme & 57 & 76 \\
Yarar görmeme & 47 & 62.7 \\
Sıkma & 30 & 40 \\
Aşağı kayma & 24 & 32 \\
Kaşındırma & 14 & 18.7 \\
Ağrı oluşturma & 11 & 14.7 \\
Pahalı maliyet & 7 & 9.3 \\
Cilt bütünlüğünü bozma & 3 & 4 \\
Estetik görünmeme & 2 & 2.7 \\
\hline
\end{tabular}

*Birden fazla şık işaretlenmiştir. 
KÇ kullanan hastaların çoğunlukla yaptıkları yanlış uygulamaları ise; gece giyme (\%88), cilt kontrolü yapmama $(\% 82,7)$, kat kat olmamasına özen göstermeme (\%48) olarak belirlendi (Tablo 4). Ayrica 31 kişi $(\% 41,3)$ KÇ’nin bedenine uyumsuz olduğunu düşünmekteydi.

Tablo 4. Hastaların Kompresyon Çorabı Kullanımında Yanlış Uygulamalarının Dağılımı

\begin{tabular}{|l|c|c|}
\hline Yanlış Uygulamalar & n* & \% \\
\hline Gece giyme & 66 & 88 \\
Cilt kontrolü yapmama & 62 & 82.7 \\
Kat kat olmasına özen göstermeme & 36 & 48 \\
KÇ üzerine çorap giyme & 5 & 6.6 \\
Giysi üzerine KÇ giyme & 1 & 1.3 \\
Yırtık KÇ kullanma & 1 & 1.3 \\
Topuk kismını doğru yerleştirememe & 1 & 1.3 \\
\hline
\end{tabular}

*Birden fazla şık işaretlenmiştir

\section{TARTIŞMA}

Çalışmamızda hastalar en sık KÇ'yi yardımsız giyemedikleri ve KÇ'nin terlettiği konusunda olumsuz görüşler belirtmiştir. Raju ve ark. (2011)'nın KÇ’yi düzenli olarak kullanmayan hastalar üzerinde yaptığ çalışmasında ve Kahn ve ark. (2003), düzensiz olarak kompresyon çorabı kullanan hastaları ele aldığı çalışmasında hastaların yüksek maliyet, terletme, çoraba ait rahatsızlık hissi, çirkin görüntü ve cilt bütünlüğünü bozma, giyim zorluğu gibi sorunlardan şikayetçi olduğu belirlenmiştir. Doktorlara göre ise hastaların KÇ kullanmak istememelerinin en büyük sebepleri; çorapların rahatsız edici olması ve giyilme zorluğu olarak belirtilmiştir (Kahn ve ark. 2003). Partsch ve ark. (2005)'nın hekimlerin görüşünü aldığı çalışmasında hastaların çoraplara karşı uyumsuzluğunun nedenleri; giyim zorluğu, yarar görmeme, estetik bulmama ve pahalı fiyat olarak sıralanmıştır. Literatürde ki bazı çalışmalarda hastaların KÇ kullanımına devam etmeme sebepleri; pahalı fiyat, terletme, kaşındırma, çirkin görünme, ödemi artırma, cilt lezyonları oluşturma ve uygulama zorluğu olarak ifade edilmiş- tir (Cataldo, Godoy ve Barros 2012; Ziaja, Kocełak, Chudek ve Ziaja 2011). Hirai, Iwata, Miyazaki, Koyama ve Nakamura (2013) çalışmasında günlük aktiviteler esnasında giyilen KÇ hakkındaki memnuniyetsizliğin nedenleri; ayak ve parmaklarda şişme, ağrı ve uyuşma, bilekte kaşıntı, sıkılık, kırışıklık, s1cak tutma, bacaktan aşağı kayma ve kozmetik olmama olarak saptanmıştır. Hastaların 3 gruba ayrılarak $\mathrm{KÇ}$ memnuniyetinin değerlendirildiği diğer bir çalışmada da diz boyu orta basınçlı (20-30 mmHg) KÇ kullanan gruptaki hastaların sikılık, sicaklık hissi ve kaşıntı gibi şikayetleri olduğu, ikinci grupta yer alan uyluk boyu düşük basınçlı KÇ (15-18 mmHg) kullanan hastalarında çorabın aşağı düştügü konusunda şikayetleri olduğu saptanmıştır (Ayhan 2012). Sonuçlarımız literatürle benzerlik göstermektedir. Bir araştırmada kompresyon çoraplarının terleme açısından konforsuzluğunu gidermek ve kullanılabilirliğini artırmak adına teri vücuttan uzaklaştırabilecek ve derinin nefes alabilirliğini sağlayacak düşük ssıl direnç, yüksek su buharı ve hava geçirgenliği özellikleri ile viskon, modal veya tencel ipliklerin $\mathrm{KÇ}$ üretiminde kullanılması önerilmiştir (Oğlakçığlu ve Marmara$112010)$.

Literatürde ameliyat sonrası hastaların \%29'unun KÇ’yi yanlış kullandığı ve \%26'sının yanlış boyutta KÇ kullandığ 1 sonucuna ulaşılmıştır (Winslow ve ark. 2008). Hameed, Browse, Immelman ve Goldberg (2002)'in çalışmasındaysa diz boyu KÇ kullanan hastaların \%70'inin, uyluk boyu KÇ kullanan hastaların ise \%35,7'sinin KÇ'yi doğru kullandığı saptanmıştır. Bu çalışma sonucunda hastaların KÇ kullanımında yanlışlarının olduğu belirlenmiştir. Cilt kontrolü yapmayan hastaların çoğunlukta $(\% 82,7)$ olduğu göz önüne alındığında, çorapların transparan üretilmesi alternatifinin cilt problemlerini hizlı tanılanabilmesine olanak sağlayabileceği öngörülmektedir (Winslow ve ark. 2008). Yalnızca gündüzleri kullanılmas1 gereken KÇ'lerin hastalar tarafından yüksek oranla gece de kullanıldığı ve hastaların \%40'ının KÇ kullanma amacını bilmediği veya yanlış bildiği saptandığından hastaların KÇ kullanımı hakkında yeteri kadar 
bilgilendirilmediği düşünülmektedir. Winslow ve ark. (2008)'nın çalışmasında kompresyon çorabı kullanıcılarının \%20'sinin çorap kullanımının amacını bilmedikleri saptanmıştır. Dolayısıyla hastalar ile en çok zaman geçiren hemşirelerin yanlış uygulamaları engellemek ve yararlılığı artırmak adına hastaları detaylı bilgilendirmesini öneriyoruz.

Benkö, Cooke, McNally, Mollan (2001) diz boyu KÇ’lerin uyluk boyu KÇ’lere nazaran daha kolay giyildiği ama tüm çoraplarının kullanımın zor olduğu sonucuna varılmıştır. Kullanım kolaylığı ve ucuz oluşu, rahatlığı sebebiyle diz boyu KÇ'ler ameliyat sonras1 dönemde kullanılabilir (Autar 2009; Dirimeşe, Yavuz, Kismalı ve Turna 2013).

\section{SONUÇ VE ÖNERILER}

Uygun tromboprofilaksinin kullanımı DVT'nin hastanede ölümlerin önlenebilir nedenidir (Morrison 2006). Risklerin önceden belirlenerek önlem alınması hem hastanın yaşam kalitesini artıracak, hem iş yükünü azaltacak, hem de ekonomik tasarruf sağlayacaktır (Doruk, Naharc1, Safer, Bozoğlu ve Taşçı 2011). Hemşireler eğitim ve psikolojik destek sağlayarak yapılan kaliteli hemşirelik müdahaleleriyle yaşam kaybı$\mathrm{n} 1$ engellemektedir. $\mathrm{Bu}$ rolleriyle hemşireler trombozun önlenmesinde ön safta yer alırlar (Morrison 2006). Hemşireler, KÇ kullanacak hastaların uygun boyutta ve doğru bir şekilde KÇ kullanılmasından ve nas1l giyeceği konusunda eğitim verilmesinden sorumludur (Winslow ve ark. 2008). Ayrıca KÇ'nın standartlarını, uygulama prosedürünü ve komplikasyonlarını bilmelidir (Hayes, Lehman ve Castonguay 2002). Bu anlamda hemşirelik bakım kalitesi ve hasta güvenliği için güncel verilerden yararlanılmalıdır (Dirimeşe ve Yavuz 2010).

Çalışmamızda hastaların KÇ kullanımında yanlış uygulamaları olduğu belirlenmiş ve bu sonuçlar doğrultusunda önerilerimiz şu şekilde belirtilmiştir.

- Sağlık profesyonelleri KÇ'nin uygun kullanımı hakkında hastaları bilgilendirmeli, hastaların $\mathrm{KC}$ kullanımını gözlemlemeli ve yanlış uygulamaları düzeltmelidir.
- Kompresyon çorabı üretici firmalar, hastaların bu konuda yaşadıkları problemleri göz önüne bulundurmalıdır.

- Çalışmalar farklı ve daha fazla örneklem gruplarında tekrarlanmalıdır.

\section{KAYNAKLAR}

Altıntaş, F. ve ark. (2008). Majör ortopedik cerrahilerde venöz tromboemboli profilaksisi: Çok merkezli, prospektif, gözlem çalı̧̧mas1. Acta Orthop Traumatol Turc, 42(5): 322-327.

Autar, R. (2009). A review of the evidence for the efficacy of antiembolism stockings (AES) in venous thromboembolism (VTE) prevention. Journal of Orthopaedic Nursing, 13(1): 41-49.

Aydın, Z. ve ark. (2005). Nöroşirurji hastalarında antikoagülan tedavi. Ankara Üniversitesi Tıp Fakültesi Mecmuası, 58(2): 90-95.

Ayhan, H. (2012). Yüksek riskli gruplarda postoperatif derin ven trombozunu önleme protokollerinin karşılaştırılması. Yayınlanmış Doktora Tezi, Gülhane Askeri Tıp Akademisi, Ankara.

Benkö, T., Cooke, E. A., McNally, M. A., Mollan, R. A. (2001). Graduated compression stockings: Knee length thigh length. Clinical Orthopaedics and Related Research, 383: 197-203.

Bozkurt, K. A. ve ark. (2008). Kronik venöz yetersizlik. Bozkurt, K. A. (Ed.). Türk Kalp Damar Cerrahisi Derneği Periferik Arter ve Ven Hastalıkları Tedavi Kılavuzu. Güneş Kitabevi, Ankara, 96127.

Cataldo, J. L., Godoy, J. M., Barros, N. (2012). The use of compression stockings for venous disorders in Brazil. Phlebology, 27: 33-37.

Dennis, M. ve ark. (2009). Effectiveness of thigh-length graduated compression stockings to reduce the risk of deep vein thrombosis after stroke (CLOTS trial 1): A multi centre, randomised controlled trial. Lancet, 373(9679): 1958-1965.

Dirimeşe, E., Yavuz, M. (2010). Cerrahi kliniklerde venöz tromboembolinin önlenmesi. Maltepe Üniversitesi Hemşirelik Bilim ve Sanatı Dergisi, 2(3): 98-105.

Dirimeşe, E., Yavuz, M., Kısmalı, E., Turna, B. (2013). The effect of knee length and thigh length antiembolism stockings on deep vein thrombosis prophylaxis. Türk Gögüs Kalp Damar Cerrahisi Dergisi, 21(2): 325-332.

Doruk, H., Naharcı, M., Safer, U., Bozoğlu, E., Taşçı, İ. (2009). Yaşlilarda derin ven trombozu. Lancet, 373(9679): 1958-1965.

Geerts, W. H. ve ark. (2004). Prevention of venous thromboembolism: The seventh ACCP conference on antithrombotic and thrombolytic therapy. CHEST Journal, 126(3): 338-400. 
Hameed, M. F., Browse, D. J., Immelman, E. J., Goldberg, P. A. (2002). Should knee-length replace thigh-length graduated compression stockings in the prevention of deep-vein thrombosis? $S$ Afr J Surg, 40(1): 15-16.

Hayes, J., Lehman, C., Castonguay, P. (2002). Graduated compression stockings: Updating practice, improving compliance. Medsurg Nursing, 11(4): 163-167.

Hirai, M., Iwata, H., Miyazaki, K., Koyama, A., Nakamura, H. (2013). Development of separated elastic stockings. Phlebology, 28(4): 201-208.

Kahn, S. R., Elman, E., Rodger, M. A., Wells, P. A. (2003). Use of elastic compression stockings after deep venous thrombosis: A comparison of practices and perceptions of thrombosis physicians and patients. Journal of Thrombosis and Haemostasis, 1(3): 500550 .

Kurtoğlu, M., Sivrikoz, E. (2008). Derin ven trombozu: Tan1, tedavi, profilaksi. Harran Üniversitesi Tıp Fakültesi Dergisi, 5(1): 34-42.

Lassila, R. (2013). Prevention of venous thromboembolism. EBM Guidelines, Evidence-Based Medicine, EBM Guidelines, Duodecim Medical Publications Ltd., http://www.ebm-guidelines.com/ dtk/ebmg/koti?p_artikkeli=ebm00109 (15.01.2015).

Milli Eğitim Bakanlığı (2012). Kardiyovasküler sistem cerrahisinde bakım. Milli Eğitim Bakanlığı yayınları, Ankara, http:// http://www.megep.meb.gov.tr/mte_program_modul/moduller_pdf/Kardio-vask $\%$ C3\%BCler\%20Sistem $\% 20$ Cerrahisinde $\% 20$ Bak\%C4\%B1m.pdf (10.02.2015).

Morrison, R., (2006). Venous thromboembolism: Scope of the problem and the nurse's role in risk assesment and prevention. Journal of Vascular Nursing, 24(3): 82-90.

National Institute for Health and Clinical Excellence (NICE) (2010). Venous thromboembolism: Reducing the risk, reducing the risk of venous thromboembolism (deep vein thrombosis and pulmonary embolism) in patients admitted to hospital. NICE clinical guideline, 92, http://www.1000livesplus.wales.nhs.uk/sitesplus/documents/1011/CG92NICEGuidelinePDF.pdf (12.04.2015).

National Institute for Health and Clinical Excellence (NICE) (2012). Venous thromboembolism: Reducing the risk evidence update, https://www.nice.org.uk/guidance/cg92/evidence/evidenceupdate-243917533 (15.02.2015).

Nicolaides, A. N. ve ark. (2008). Management of chronic venous disorders of the lower limbs: Guidelines according to scientific evidence. International Angiology, 27(1): 1-59.

Oğlakçıŏlu, N., Marmaralı, A. (2009). Kompresyon çorapları ve basınç tedavisi. Tekstil Teknolojileri Elektronik Dergisi, 3(3): 8494.
Oğlakçığlu, N., Marmaralı, A. (2010). Rejenere selüloz liflerinin kompresyon çoraplarının 1sıl konfor özelliklerine etkisi. The Journal of Textiles and Engineer, 17(77): 6-12.

Özbayrak, N. (2009). Varis çoraplarının performans özelliklerinin incelenmesi. Yüksek Lisans Tezi, Uludağ Üniversitesi Fen Bilimleri Enstitüsü, Bursa.

Partsch, B., Pannier, F., Partsch, H., Rabe, B. (2005). Kompressionsstrümpfe nach tiefer Beinvenenthrombose im internationalen Vergleich-Ergebnisse einer Fragebogenumfrage. Vasomed, 17(3): 82-87.

Raju, S., Hollis, K., Neglen, P. (2007). Use of compression stockings in chronic venous disease: Patient compliance and efficacy. Ann Vasc Surg, 21(6): 790-795.

Sachdeva, A., Dalton, M., Amaragiri, S. V., Lees, T. (2010). Elastic compression stockings for prevention of deep vein thrombosis. Cochrane Database Syst Rev,. 7(7): 2.

Sage, S. L., McGee, M., Emed, J. D. (2008). Knowledge of venous thromboembolism prevention among hospitalized patients. J Vasc Nurs., 26: 109-117.

Sajid, M. S., Desai, M., Morris, R. W., Hamilton, G. (2012). Knee length versus thigh length graduated compression stockings for prevention of deep vein thrombosis in postoperative surgical patients. Cochrane Database Syst Rev., 5(CD007162): 1-17.

Samama, M. M., Dahl, O. E., Quinlan, D. J., Mismetti, P., Rosencher, N. (2003). Quantification of risk factors for venous thromboembolism: A preliminary study for the development of a risk assessment tool. Haematologica, 88(12): 1410-1421.

Sarıgül, A., Tanyeli, Ö. (2007). Derin ven trombozunda güncel tedavi yaklaşımları. Türk Göğüs Kalp Damar Cerrahisi Dergisi, 15(4): 316-321.

Scottish Intercollegiate Guidelines Network (2010). Prevention and management of venous thromboembolism: A national clinical guideline, http://www.sign.ac.uk/pdf/sign122.pdf (15.02.2015).

Şerifoğlu, R., Bilgen, S., Atıcı, T., Bilgen, Ö., Yılmazlar, A. (2007). Artroplastide derin ven trombozu profilaksisinde aktif ve erken hareketin etkinliği. Uludağ Üniversitesi Tıp Fakültesi Dergisi, 33(3): 127-134.

Taylan, S. (2008). Venöz ülserlerden korunma ve hemşirelik bak1mı. Erdost, Ş., Çetinkale, O. (Eds.). Yara Bakımı ve Tedavisi. İ.Ü Cerrahpaşa Tıp Fakültesi Sürekli Tıp Eğitimi Etkinlikleri Sempozyum Dizisi, İstanbul, 69-75.

The Joanna Briggs Institute (2008). Best practice evidence based information sheets for health professionals, graduated comprassion stockings for the prevention of postoperative venous thromboembolism. Best Practice, 12(4): 1-4. 
Thenganatt, J., Geerts, W. (2006). Prevention of venous thromboembolism in surgical patients: Why and how? Techniques in Regional Anesthesia and Pain Management, 10(2): 40-45.

Vascular Disease Foundation (2012). Deep vein thrombosis and post thrombotic syndrome, http://vasculardisease.org/flyers/focuson-compression-stockings-flyer.pdf (20.03.2015).

Walker, L., Lamont, S. (2008). Graduated compression stockings to prevent deep vein thrombosis. Nursing Standard, 22(40): 3538.
Winslow, E. H., Debra, L., Brosz, D. L. (2008). Graduated compression stockings in hospitalized postoperative patients: Correctness of usage and size. $A J N, 108(9)$ : 40-50.

Whitley, L. (2002). Graduated compression hosiery. Harman, R. J. (Ed.). Patient Care in Community Practice: A Handbook of NonMedicinal Healthcare. 2nd ed., Pharmaceutical Press, London, 63-78.

Ziaja, D., Kocełak, P., Chudek, J., Ziaja, K. (2011). Compliance with compression stockings in patients with chronic venous disorders. Phlebology, 26(8): 353-360. 